\title{
Prosody meets pragmatics: a production study on German verb-first sentences
}

\author{
Daniela Wochner \& Nicole Dehé \\ Department of Linguistics, University of Konstanz, Germany \\ Daniela.Wochner@uni-konstanz.de, Nicole.Deheluni-konstanz.de
}

\begin{abstract}
This study investigates the prosodic differences of German string-identical verb-first sentences with different pragmatic meanings, i.e. exclamatives (EX: Kann die Lene malen! 'Can Lene paint!'), rhetorical questions (RQ: Kann die Lene malen?!) and information-seeking questions (ISQ: Kann die Lene malen?). We report on whether and how the pragmatic distinction is marked in the speech signal.

The main results show that EXs and ISQs for the most part hold opposing feature characteristics whereas the prosodic characteristics of RQs seem to lie in-between. EXs are mainly realized with a falling intonation contour, ISQs with a rising one and RQs with a plateau contour. In terms of the number of prenuclear pitch accents, RQs are placed in-between EXs with most accents and ISQs with fewest accents. Similarly, regarding the pitch range of the prenuclear accents: RQs are placed between EXs (largest expansion) and ISQs (smallest expansion). A similar picture arises regarding duration with EXs showing the longest and ISQs the shortest constituent durations. We assume two scales for the classification of the pragmatic function of verb-first sentences with regard to prosody: an interrogativity scale and a scale of emphasis. In both scales, RQs are placed between the two extremes (EXs and ISQs).
\end{abstract}

Index Terms: prosody, intonation, pragmatics, German

\section{Introduction}

This study reports on a production-experiment that investigates the prosodic differences of string-identical German verb-fist sentences with different pragmatic meanings.

\subsection{The three pragmatic functions}

Exclamatives express an attitude of surprise. When uttering an EX, the speaker indicates that $\mathrm{s} / \mathrm{he}$ is surprised that the proposition $p$ violates her/his expectation of a given situation [1], that the proposition of her/his utterance is unexpected and divergent from the alleged norm [2]. Additionally, EXs receive a degree interpretation, meaning that the content of an EX "must $[\ldots]$ be about a degree" $[1,3]$. In Kann die Lene malen! ("Can Lene paint!"), for instance, the degree manifests itself in the quality of Lene's artistically skills. Exclamative verb-first sentences are claimed to be non-interrogatives or "marked declaratives" [4] - declaratives with verb-first syntax.

A common description of RQs is that the answer is already known/ inferable for the addressee (c.f., [5], [6]). RQs express a strong speaker belief towards the intended proposition. By uttering an RQ, the speaker insinuates the opposite polarity of what is expressed by [7]. That is, by uttering Kann die Lene malen?! ("Can Lene paint?!") as an RQ, the speaker signals his/her strong belief that Lene cannot paint. The effect of an RQ is similar [5] to the effect of a default assertion (e.g., [8]).

By uttering a genuine ISQ, the speaker signals a cognitive deficit ([9], [10]) or a knowledge gap s/he seeks to remediate. In other words, the speaker does not know the answer to an ISQ and intends to elicit a response from the addressee(s). Following [9], the meaning of a question is defined in the set of answers containing the positive proposition $p$ and the negative proposition $\neg p$. The expected answer to e.g. Kann die Lene malen? ('Can Lene paint?') may be either 'yes' or 'no'. Neutral ISQs are usually non-emphatic.

\subsection{Prosodic background}

Semantic-pragmatic and prosodic literature agree on the idea that RQs differ from ISQs prosodically ([7], [11], [12], [5]). However, empirical studies on the matter have been scarce and many claims are based on introspective assumptions. A recent study on the prosody of string-identical RQs and ISQs in German ([13], [14]), however, reveals some clear phonological and phonetic differences between the two question types. Especially with regard to the nuclear contour, e.g., polar RQs are more frequently produced with a plateau contour $\left(\mathrm{L}^{*}+\mathrm{H} \mathrm{H}-\right.$ $\%)$ as opposed to a continuous rise $\left(\mathrm{L}^{*} \mathrm{H}-{ }^{\wedge} \mathrm{H} \%\right)$ in ISQs, and they are produced with longer constituent durations and breathier voice quality than ISQs. Comparable results are reported for English in a study by [15]. Here, polar RQs differed from ISQs with regard to the final boundary tone and the position of the nuclear accent. Phonetically, polar RQs were longer in duration. With regard to the prenuclear field a prestudy already revealed that RQs are more commonly produced with a prenuclear accent than ISQs, which are also larger in pitch expansion [16].

Results of a study by [17] revealed similar results for emphatic questions and utterances of surprise: a breathier voice quality and lengthening of parts of the utterances. However, unlike RQs, which show a shallower (plateau) intonation contour than ISQs, emphatic questions end in a steeper and higher rise than non-emphatic questions. Additionally, a study by [18] showed that utterances of surprise are realized with a raising of the F0 maxima, possibly with an emphatic pitch peak (e.g., [19]). [20] also state segmental lengthening for utterances of surprise. A production experiment by [21] confirms a longer utterance duration for $w h$-exclamatives in comparison to stringidentical $w h$-interrogatives. A particular, yet disputed, feature of EXs is the so-called exclamative accent, an emphatic pitch peak in the prenuclear region, which is not assigned to a fixed position ([21], [22]).

Polar ISQs in German are generally assumed to manifest a low-rising contour $\left(\mathrm{L}^{*} \mathrm{H}-{ }^{\wedge} \mathrm{H} \%,[23,24]\right)$.

Interestingly, the pragmatic types that are off the beaten track of the default interpretation (i.e., a neutral question) of a German interrogative sentence seem to share certain prosodic features, e.g., durational features. 


\subsection{Hypotheses}

Based on the introduction given above, we hypothesize that (i) RQs predominantly end in a high boundary tone reflecting their interrogative status, whereas EXs terminate in a low boundary tone, reflecting their marked-declarative status. (ii) Due to their expressive nature, we expect RQs to show an emphatic pitch peak in the prenuclear region similar to EXs, however with less pitch expansion. (iii) RQs and EXs both display longer durations than ISQs. (iv) We hypothesize that the prosody of an RQ may not actually signal only rhetoricity, but, more generally, a certain kind of expressively/ emphatically marked question.

\section{The experiment}

A production experiment was designed to test whether and how speakers prosodically differentiate between two expressive verb-first sentence types (RQs and EXs) compared to a neutral verb-first form (ISQs).

\subsection{Materials}

We created 16 target verb-first sentences with the same metrical structure: a trochee. All sentences started with a light verb (e.g., kann - 'can', see Table 1) followed by the subject determiner phrase (e.g, die Lene 'DET Lene'). The sentence-final constituent, on which we expected the placement of the nuclear accent, was either an adjective or a full verb. None of the sentences was lexically marked by any item which would favor a specific kind of pragmatic meaning (e.g. a modal particle or negative polarity items favoring an RQ). In order to obtain a consistent signal to better separate pitch accent type and boundary tone, the final constituent was mainly sonorous and lexical stress was on the penultimate syllable.

In the experimental paradigm, all target sentences were preceded by context situations triggering one of three different pragmatic readings (neutral ISQ, EX, RQ; see Table 1). The context for an exclamative reading of the target was created such that the speaker was surprised or struck by $p$. The context for a rhetorical reading of the target was done such that the speaker was sure about $p$ and assumes that $p$ should be known by the interlocutor(s). Finally, the context for an informationseeking reading of the target sentence was created such that the speaker did not know whether the proposition of the target sentences was true $(p)$ or not $(\neg p)$. Eventually, for each target sentence, there were three string-identical versions with different pragmatic meanings $(\mathrm{N}=48)$.

Contexts were kept as short and informative as possible. Furthermore, all contexts contained the verb that was in verbfirst-position of the target sentence, the subject NP and the sentence final constituent of the target sentence, thus all constituents of the target utterance were lexically given. This was done in order to prevent focal accents.

Additionally, we created 24 filler sentences and contexts, whose make-up was similar to the target contexts but did not follow any experimental hypothesis. At the beginning of each test phase, we added 4 practice sentences and contexts that explicitly evoked a rhetorical, an information-seeking or an exclamative reading by means of discourse markers and lexical items such as modal particles. Target and filler trials, however, did not contain any sort of lexical material to indicate the actual proposition. In the experimental procedure, the targets of each triplet (ISQ, RQ and EX) were separated by at least 4 other target or filler trials.
Table 1: Context triplet with target sentence; target identical for all three contexts.

\begin{tabular}{|c|c|}
\hline & Context \& Target \\
\hline $\begin{array}{c}\text { Exclamative } \\
\text { (surprise) }\end{array}$ & $\begin{array}{l}\text { You and a friend are visiting the } \\
\text { atelier of your mutual friend Lene and } \\
\text { you are surprised how good she is at } \\
\text { painting. } \\
\text { You say to your friend: }\end{array}$ \\
\hline $\begin{array}{c}\text { Rhetorical } \\
\text { question } \\
\text { (belief) }\end{array}$ & $\begin{array}{l}\text { Your friend wants your roommate } \\
\text { Lene to paint a picture for a friend. } \\
\text { However, it is well known that Lene is } \\
\text { very bad at painting. } \\
\text { You say to your friend: }\end{array}$ \\
\hline $\begin{array}{l}\text { Information- } \\
\text { seeking } \\
\text { question } \\
\text { (lack of } \\
\text { information) }\end{array}$ & $\begin{array}{l}\text { You want to give your friend's } \\
\text { daughter Lene crayons for her } \\
\text { birthday. However, you do not know } \\
\text { whether the little girl already paints } \\
\text { pictures or not. } \\
\text { You say to your friend: }\end{array}$ \\
\hline Target sentence & $\begin{array}{l}\text { Kann die Lene malen 'Can Lene } \\
\text { paint' }\end{array}$ \\
\hline
\end{tabular}

\subsection{Procedure}

We conducted the experiment with 12 native speakers of German ( 7 female, average age 22.6 years, $S D=2.9$ ). They were students at the University of Konstanz and were paid a small reimbursement for their participation. They were tested in a sound-attenuated booth at the PhonLab laboratory of the University of Konstanz.

Sentence type was manipulated within subjects. Each participant produced each sentence in all three conditions. Context situations and target sentences were presented on a computer screen using Presentation (Neurobehavioral-Systems 2001). Context situations were presented in black Calibri 40 font and target sentences in blue Calibri 40 font, all on white background. The participants were first presented with the context situations before the target utterance was added to the same slide by pressing a button on a button box (self-paced). They were instructed to read each context situation carefully and to utter the target and filler sentences as naturally as possible. After reading the contexts and uttering the targets, the participants turned to the next trial by pressing the button again. They were allowed to repeat the sentences in case they spluttered or mispronounced.

Each experimental run started with a practice phase to make it easier for participants to engage with the task. After this phase, they were allowed to ask questions.

Participants were wearing dynamic headset-microphones (Shure SM10A) and were recorded with an USB sound interface (Audient iD14). A sampling rate of $44.1 \mathrm{kHz}$ and a resolution of 16 Bit was used in all recordings. The participants did not receive any feedback during the test phase.

\subsection{Data treatment and analyses}

Overall, we recorded 576 ISQs, EXs and RQs. 35 items had to be excluded due to glottalization or infelicitous productions. We analyzed the remaining 541 productions (EX: 180, RQ: 176, ISQ: 185) phonologically and phonetically using Praat [25]. All files were labeled at the level of morphological word, syllable and segment. We annotated pitch accents and boundary tones following the guidelines of GToBI [23, 24]. All pitch values for calculation of $\mathrm{F} 0$ in ranges were extracted 
automatically using a Praat script. Pitch was extracted within the range of the subject noun and the final constituent. All points for pitch measurements were set manually.

For the statistical analysis of boundary tones and pitch accents, we ran a series of linear mixed effect regression models with illocution-type (EX, RQ and ISQ) as fixed factors and participants and items as crossed-random factors. For dependent variables with more than one level, one level was coded 1 and all other levels 0 . The effects of the fixed factors were calculated for these modified dependent variables [26]. For the statistical analysis of durations and pitch range we ran linear mixed effect regression models with the same specifications and model fitting as described above. P-values were calculated using the Satterthwaite approximation in the Rpackage lmerTest and were adjusted by means of the Benjamini-Hochberg correction [27].

\subsection{Results}

\subsubsection{Phonological results}

Final boundary tone

In EXs contours are mainly terminated by the low boundary tone L-\% (Figure 1). L-\% occurs significantly more often in EXs than in RQs $(\beta=4.9, \mathrm{SE}=0.5, \mathrm{z}=9.8, \mathrm{p}<0.0001)$ and ISQs $(\beta=8.1, \mathrm{SE}=0.8, \mathrm{z}=9.6, \mathrm{p}<0.0001)$. RQs significantly more often end in $L-\%$ than ISQs ( $\beta=3.1, \mathrm{SE}=0.6, \mathrm{z}=4.9, \mathrm{p}<0.0001$ ).

RQs mainly end in the rising edge tone $\mathrm{H}-{ }^{\wedge} \mathrm{H} \%$. They do so less frequently than ISQs $(\beta=-3.4, \mathrm{SE}=0.4, \mathrm{z}=-8.3, \mathrm{p}<0.0001)$ but more often than EXs ( $\beta=3.2, \mathrm{SE}=0.4, \mathrm{z}=7.8, \mathrm{p}<0.0001)$. RQs also frequently end in a plateau contour (Figure 2), more often than EXs $(\beta=2.9, \mathrm{SE}=0.6, \mathrm{z}=5.2, \mathrm{p}<0.0001)$ and ISQs $(\beta=4.4, \mathrm{SE}=1.0, \mathrm{z}=4.2, \mathrm{p}<0.0001)$. ISQs almost exclusively terminate in $\mathrm{H}-{ }^{\wedge} \mathrm{H} \%$. See Table 2 for the distribution of boundary tones.

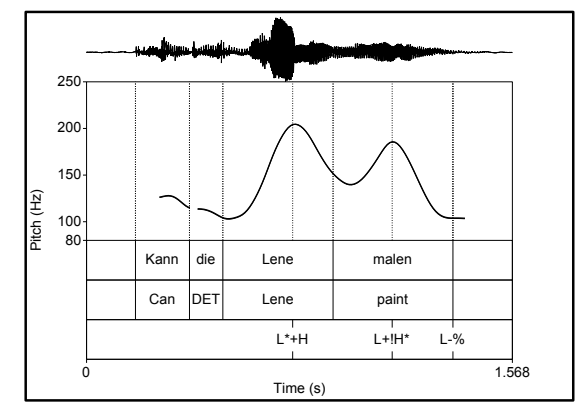

Figure 1: Example of Kann die Lene malen 'Can Lene paint' in exclamative condition.

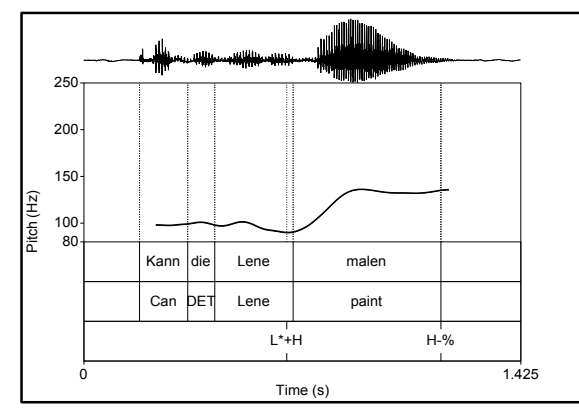

Figure 2: Example of Kann die Lene malen 'Can Lene paint' in rhetorical illocution.
Table 2: Distribution of the most frequent boundary tones.

\begin{tabular}{cccc}
\hline $\begin{array}{c}\text { Boundary } \\
\text { tones }\end{array}$ & $\begin{array}{c}\text { EX } \\
(\mathrm{N}=180)\end{array}$ & $\begin{array}{c}\text { RQ } \\
(\mathrm{N}=176)\end{array}$ & $\begin{array}{c}\text { ISQ } \\
(\mathrm{N}=185)\end{array}$ \\
\hline $\mathrm{L}-\%$ & $160(89 \%)$ & $34(19 \%)$ & $4(2 \%)$ \\
$\mathrm{H}-{ }^{\wedge} \mathrm{H} \%$ & $14(8 \%)$ & $88(50 \%)$ & $174(94 \%)$ \\
$\mathrm{H}-\%$ & $4(2 \%)$ & $42(24 \%)$ & $1(0.5 \%)$ \\
\hline
\end{tabular}

Nuclear accents

The most common nuclear accent type in EXs is $\mathrm{L}+$ ! $\mathrm{H}^{*}$. It occurs significantly more often in EXs than in RQs $(\beta=2.6$, $\mathrm{SE}=0.5, \mathrm{z}=5.8, \mathrm{p}<0.0001)$ and almost never in ISQs. RQs are mainly realized with the low nuclear accent $L^{*}$, significantly more often than $\operatorname{EXs}(\beta=1.8, \mathrm{SE}=0.2, \mathrm{z}=6.8, \mathrm{p}<0.0001)$ but less often than ISQs $(\beta=-2.6, \mathrm{SE}=0.3, \mathrm{z}=-7.8, \mathrm{p}<0.0001)$. RQs are also often produced with an $\mathrm{L}^{*}+\mathrm{H}$ nuclear accent which does not occur in ISQs at all. This accent type is more frequent in RQs than in EXs $(\beta=1.8, \mathrm{SE}=0.5, \mathrm{z}=3.4, \mathrm{p}<0.001)$. Table 3 displays the distribution of the most common nuclear accents.

Table 3: Distribution of the most frequent nuclear accents.

\begin{tabular}{cccc}
\hline $\begin{array}{c}\text { Nuclear } \\
\text { accents }\end{array}$ & $\begin{array}{c}\text { EX } \\
(\mathrm{N}=180)\end{array}$ & $\begin{array}{c}\text { RQ } \\
(\mathrm{N}=176)\end{array}$ & $\begin{array}{c}\text { ISQ } \\
(\mathrm{N}=185)\end{array}$ \\
\hline $\mathrm{L}+! \mathrm{H}^{*}$ & $72(40 \%)$ & $13(7 \%)$ & $1(0.5 \%)$ \\
$\mathrm{L}^{*}$ & $34(19 \%)$ & $94(53 \%)$ & $171(92 \%)$ \\
$\mathrm{L}+\mathrm{H}^{*}$ & $24(13 \%)$ & $6(3 \%)$ & $5(3 \%)$ \\
$\mathrm{L}^{*}+\mathrm{H}$ & $16(9 \%)$ & $46(26 \%)$ & $0(0 \%)$ \\
none & $10(6 \%)$ & $12(7 \%)$ & $5(3 \%)$ \\
\hline
\end{tabular}

Prenuclear accents

The majority $(>50 \%)$ of prenuclear accents across all illocutiontypes are associated with the subject NP (e.g, Lene in 'Can Lene paint'). If a prenuclear is present, the most frequent one in EXs and RQs is $\mathrm{L}^{*}+\mathrm{H}$, which occurs significantly more often in EXs than in RQs $(\beta=1.6, \mathrm{SE}=0.7, \mathrm{z}=2.1, \mathrm{p}=0.0316)$. EXs also often show $\mathrm{L}+\mathrm{H}^{*}$ prenuclear accents, significantly more often than RQs $(\beta=2.0, S E=0.6, z=3.6, p<0.001)$ and ISQs $(\beta=2.8, S E=0.8$, $\mathrm{z}=3.7, \mathrm{p}<0.001)$. Prenuclear accents associated with the verb in verb-first position $(>35 \%)$ are mainly $\mathrm{H}^{*}$ accents across all illocution-types.

Table 4: Distribution of the most frequent prenuclear accents.

\begin{tabular}{cccc}
\hline $\begin{array}{c}\text { prenuclear } \\
\text { accents }\end{array}$ & $\begin{array}{c}\text { EX } \\
(\mathrm{N}=180)\end{array}$ & $\begin{array}{c}\text { RQ } \\
(\mathrm{N}=176)\end{array}$ & $\begin{array}{c}\text { ISQ } \\
(\mathrm{N}=185)\end{array}$ \\
\hline none & $90(50 \%)$ & $127(72 \%)$ & $162(88 \%)$ \\
$\mathrm{L}^{*}+\mathrm{H}$ & $56(31 \%)$ & $29(17 \%)$ & $0(0 \%)$ \\
$\mathrm{L}^{+} \mathrm{H}^{*}$ & $25(14 \%)$ & $4(2 \%)$ & $2(1 \%)$ \\
$\mathrm{H}^{*}$ & $5(3 \%)$ & $12(7 \%)$ & $13(7 \%)$ \\
\hline
\end{tabular}

\subsubsection{Phonetic results: pitch range and duration}

Pitch range of the final rises

Regarding the $\mathrm{H}-{ }^{\wedge} \mathrm{H} \%$ boundary tone, the average pitch range in EXs $(\mathrm{N}=14(8 \%)$ is 9.4st, which is significantly larger than the pitch range in RQs $(\mathrm{N}=88(50 \%))$, which is on average $8.9 \mathrm{st}$ $(\beta=1.8, \mathrm{SE}=0.8, \mathrm{t}=-2.3, \mathrm{p}=0.0211)$. ISQs $(\mathrm{N}=174(94 \%))$ show 
the largest pitch expansion with on average 11.3st, which is significantly larger than in RQs $(\beta=2.3, \quad S E=0.4, t=6.0$, $\mathrm{p}<0.0001$ ). It is also larger than in EXs, but not significantly.

Pitch range in $\mathrm{H}-\%$ is generally narrower than in $\mathrm{H}-{ }^{\wedge} \mathrm{H} \%$ $(\mathrm{EX}=4.7 \mathrm{st}, \mathrm{RQ}=6.6 \mathrm{st})$.

\section{Pitch range in the prenuclear field}

The pitch range in prenuclear accents aligned with the subject $\mathrm{NP}$ are largest in EXs, with an average of 6.4st. This is significantly larger than in RQs with an average range of $4.2 \mathrm{st}$ $(\beta=2.7, \mathrm{SE}=0.6, \mathrm{t}=4.7, \mathrm{p}<0.001)$ and in ISQs with an average range of 2.1 st $(\beta=4.0, S E=0.6, t=6.7, p<0.0001)$.

\section{Sentence duration}

EXs exhibit a significantly longer sentence duration than RQs $(\beta=0.07, \mathrm{SE}=0.03, \mathrm{t}=2.3, \mathrm{p}<0.05)$ and ISQs $(\beta=0.2, \mathrm{SE}=0.04$, $\mathrm{t}=5.5, \mathrm{p}<0.0001)$. RQs are significantly longer than ISQs $(\beta=0.1, \mathrm{SE}=0.03, \mathrm{t}=4.6, \mathrm{p}<0.001)$. This relation in durational differences holds for the verb in verb-first position and the noun but not for the determiner and the final constituent where there are no statistically significant differences between EXs and RQs $(p=0.2, p=0.3)$. Determiners are significantly shorter in ISQs than in EXs $(\beta=-0.04, \mathrm{SE}=0.01, \mathrm{t}=4.9, \mathrm{p}<0.001)$ and RQs $(\beta=0.03, \mathrm{SE}=0.01, \mathrm{t}=3.3, \mathrm{p}<0.01)$. The final constituents (verb/ adverb) are significantly shorter in ISQs than in EXs $(\beta=-0.07$, $\mathrm{SE}=0.02, \mathrm{t}=-2.9, \mathrm{p}=0.0101)$ and $\mathrm{RQs}(\beta=-0.05, \mathrm{SE}=0.01, \mathrm{t}=-$ $3.4, p=0.01)$. Verbs are significantly longer in EXs than in RQs $(\beta=0.01, \quad S E=0.004, \quad t=2.2, \quad p<0.05)$ and ISQs $(\beta=0.03$, $\mathrm{SE}=0.004, \mathrm{t}=9.4, \mathrm{p}<0.0001)$ and significantly longer in $\mathrm{RQs}$ than in ISQs. Nouns are significantly longer in EXs than in RQs $(\beta=0.04, \quad S E=0.01, \quad t=6.4, p<0.0001)$ and ISQs $(\beta=0.07$, $\mathrm{SE}=0.01, \mathrm{t}=11.9, \mathrm{p}<0.0001)$ and significantly longer in RQs than in ISQs $(\beta=0.03, \mathrm{SE}=0.01, \mathrm{t}=4.2, \mathrm{p}<0.01)$. Figure 3 illustrates the distribution of the different sentence constituents.

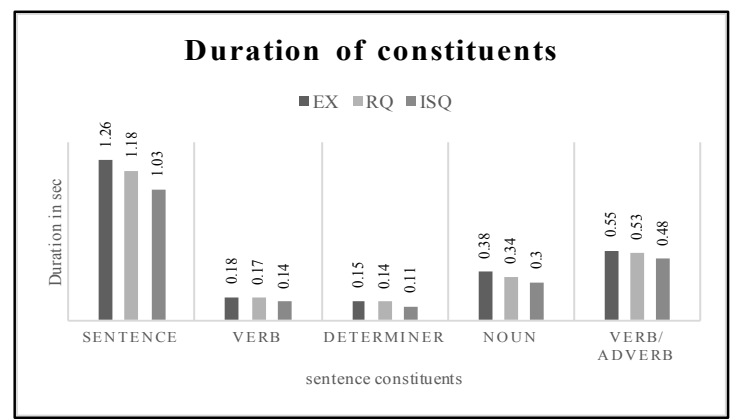

Figure 3: Duration of sentence constituents.

\section{Discussion}

The phonological analysis revealed that ISQs are characterized by a high boundary tone $\left(\mathrm{H}-{ }^{\wedge} \mathrm{H} \%\right)$ and a low nuclear accent (L*), which accords to previous results for German question prosody (e.g. [23], [28]). The results for RQs reflect the results by [13] and [14]. RQs are also mainly characterized by a rising boundary tone and a low nuclear accent, however, in $24 \%$ of the cases they end in a high plateau $\mathrm{H}-\%$. Moreover, RQs are typically produced with an $\mathrm{L}^{*}+\mathrm{H}$ nuclear accent. EXs verb-first sentences predominantly terminate in a low boundary tone (L$\%$ ), as expected. This may reflect their status as noninterrogatives or "marked declaratives" [4]. Interestingly, 19\% of the RQs terminate in a low boundary tone and $10 \%$ of the EX in a high boundary tone $\left(\mathrm{H}-\%, \mathrm{H}-{ }^{\wedge} \mathrm{H} \%\right)$, which goes against hypothesis (i). By comparison, only $2 \%$ of the ISQs end with a low or falling nuclear contour. Despite the reported differences in boundary tone between the utterance types, the overlap between them reveals that the boundary tone is a possible, but not a sufficient marker which becomes not available until late in the production of the utterance.

Regarding the rising boundary tones, speakers use a different scaling of pitch in the final parts of the three sentence types. ISQs are realized with the highest pitch expansion in $\mathrm{H}-$ ${ }^{\wedge} \mathrm{H} \%$, followed by EXs. RQs are realized with the lowest pitch range. This contradicts prior findings [16], however, it it is compatible with results by [17], who show that emphatic questions end in a higher rise than non-emphatic questions. In the present study, EXs with a rising contour did rarely manifest prenuclear pitch accents. Thus, the broad pitch range in the final part of the utterance might be an emphatic marker used by the speaker. Nevertheless, the pitch range in the plateau contour frequent in RQs is smaller than the pitch range of the rising contour in ISQs, and thus with regard to final expansion range RQs can be placed between ISQs and EXs. Final pitch scaling might thus signal interrogativity [28] and emphasis.

Most prenuclear accents were aligned with the subject in the subject NP, especially in EXs and RQs. The most frequent prenuclear accent was $\mathrm{L}^{*+} \mathrm{H}$. In the literature on German intonation this accent is linked to dedicated (and thus emphatic) or sarcastic utterances (c.f., [23], [29]). Both attributes fit to the emphasis of EXs and the often perceived sarcastic attitude of RQs. EXs and RQs show more prenuclear pitch accents, which also had a higher pitch range than ISQs. This finding supports hypothesis (ii) and we assume those prenuclear pitch accents to be emphatic pitch peaks [19], signaling pragmatic function at an early point in the utterance.

EXs and RQs are both longer than ISQs, which supports hypothesis (iii). Overall, EXs show the longest constituent duration, ISQs the shortest and RQs are placed in-between. In some sentence constituents, EXs and RQs are statistically alike in terms of duration.

The parameter-values of the feature characteristics of RQs lie between those of EXs and ISQs. We argue that they do not exclusively signal rhetoricity, but rather an increase in emphasis and a decrease in interrogativity. In other words, we assume two scales that classify verb-first sentences with regard to prosody: an interrogativity scale [28] and a scale of emphasis. EXs and ISQs can be placed at the extremes of those scales and RQs in between both extremes, which we interpret as being due to the mismatch between form (questions) and functions (assertivelike), which has been reported for RQs (c.f., [7] \& [30]). Note that while ISQs are clearly interrogatives syntactically, nonnegated verb-first EXs have been argued to be declaratives syntactically [4].

\section{Conclusions}

We assume two scales for the classification of the pragmatic function of verb-first sentences with regard to prosody: the first scale is an interrogativity scale [28] ranging from high interrogativity (ISQs) to no interrogativity (EXs). This scale is phonologically manifested in the choice of boundary tones. The second scale constitutes a range from highly expressive and emphatic (EXs) to non-emphatic (ISQs) and is visible in the durational values of the utterances and the pitch range in the prenuclear field. In both scales, RQs are placed between the two extremes (ISQs, EXs). Further research will address a perception study to elaborate on the prosodic cues listeners use to distinguish between the different pragmatic functions. 


\section{References}

[1] J. Rett, "Exclamatives, degrees and speech acts," Linguistics and Philosophy, vol. 34, pp. 411-442, 2011.

[2] N. Fries, "Ist Pragmatik schwer! - Über sogenannte Exklamativsätze im Deutschen," in Sprache und Pragmatik. vol 3, I. Rosengren, Ed., ed Lund: Veröffentlichung des Lunder Projektes „Sprache und Pragmatik“, 1988.

[3] J. Rett, "A degree account of exclamatives," presented at the Salt XVIII, Ithacam, NY, 2009.

[4] I. Rosengren, "Zur Grammatik und Pragmatik der Exklamation," in Satz und Illokution. Band 1. vol. 1, I. Rosengren, Ed., 278 ed Tübingen: Niemeyer, pp. 263-306, 1992.

[5] M. Biezma and K. Rawlins, "Rhetorical questions: Severing asking from questioning," Proceedings of SALT 27 (2017), To appear.

[6] I. Caponigro and J. Sprouse, "Rhetorical questions as questions," in Sinn und Bedeutung 11, Universitat Pompeu Fabra, Barcelona, Spain, pp. 121-133, 2007.

[7] C.-h. Han, "Interpreting interrogatives as rhetorical questions," Lingua, vol. 112, pp. 201-229, 2002.

[8] D. F. Farkas and K. B. Bruce, "On Reacting to Assertions and Polar Questions," Journal of Semantics, vol. 27, pp. 81-118, 2010.

[9] J. Groenendijk and M. Stokhof, "On the semantics of questions and the pragmatics of answers," Semantics: Critical Concepts in Linguistics, p. 288, 1985.

[10] J. Meibauer, Rhetorische Fragen. Tübingen: Niemeyer, 1986.

[11] A. Banuazizi and C. Creswell, "Is that a real question? final rises, final falls, and discourse function in yes-no question intonation," CLS, vol. 35, pp. 1-14, 1999.

[12] C. Bartels, "The intonation of English statements and questions: a compositional interpretation," Dissertation/Thesis, Garland, New York, 1999.

[13] D. Wochner, J. Schlegel, B. Braun, and N. Dehé, "The prosody of rhetorical questions in German," in Interspeech, Dresden, Germany, 2015.

[14] J. Neitsch, D. Wochner, K. Zahner, N. Dehé, and B. Braun, "Who likes liver? How German speakers use prosody to mark questions as rhetorical," presented at the Phonetics and Phonology in Europe (PaPE), 12-14 June 2017, Cologne, Germany, 2017.

[15] N. Dehé and B. Braun, "The prosody of rhetorical questions in English," Ms. submitted; University of Konstanz, 2017.

[16] D.Wochner, B.Braun, N.Dehé, "The prosody of verb-first constructions in German: A comparison of information-seeking questions, rhetorical questions and exclamatives," presented at the Phonetics and Phonology in Europe (PaPE), 12-14 June 2017, Cologne, Germany, 2017.

[17] O. Niebuhr, J. Bergherr, S. Huth, C. Lill, and J. Neuschulz, "Intonationsfragen hinterfragt - Die Vielschichtigkeit der prosodischen Unterschiede zwischen Aussage- und Fragesätzen mit deklarativer Syntax," Zeitschrift für Dialektologie und Linguistik, vol. 77, pp. 304-346, 2010.

[18] R. Kehrein, "The Prosody of Authentic Emotions," in Speech Prosody, April 11-13 2002, Aix-en-Provence, France, pp. 423426, 2002.

[19] D. R. Ladd, Jr. and R. Morton, "The perception of intonational emphasis: continuous or categorical?," Journal of Phonetics, vol. 25, pp. 313-342, 1997.

[20] K. Kohler and O. Niebuhr, "The phonetics of emphasis," in Proceedings of the 16th ICPhS, Saarbrücken, Germany, pp. 2145 2148, 2007.

[21] S. Repp, "On the acoustics of wh-exclamatives and whinterrogatives: Effects of information structure and sex of speaker," in Proceedings of the 18th International Congress of Phonetic Sciences, Glasgow, UK, pp. 1-5, 2015.

[22] H. Altmann, "Zur Problematik der Konstitution von Satzmodi als Formtypen," in Satzmodus zwischen Grammatik und Pragmatik, J. Meibauer, Ed., ed Tübingen: Niemeyer, 1987, pp. 22-56.

[23] M. Grice and S. Baumann, "Deutsche Intonation und GToBI," Linguistische Berichte, vol. 191, pp. 267-298, 2002.
[24] M. Grice, S. Baumann, and R. Benzmüller, "German Intonation in Autosegmental-Metrical Phonology.," in Prosodic Typology. The Phonology of Intonation and Phrasing, J. Sun-Ah, Ed., ed Oxford: Oxford University Press, pp. 55-83, 2005.

[25] P. Boersma and D. Weenink, "Praat: doing phonetics by computer [Computer program]," ed, 1992-2016.

[26] A. Agresti, Categorical data analysis. New Zork: Wiley, 2002.

[27] Y. Benjamini and Y. Hochberg, "Controlling the false discovery rate: A practical and powerful approach to multiple testing," Journal of the Royal Statistical Society, vol. 57, pp. 289-300, 1995.

[28] J. Michalsky, Frageintonation im Deutschen. Zur intonatorischen Markierung von Interrogativität und Fragehaltigkeit. Berlin, New York: De Gruyter, 2017.

[29] N. Lommel and J. Michalsky, "Der Gipfel des Spotts. Die Ausrichtung von Tonhöhengipfeln als intonatorisches Indiz für Sarkasmus. In Diversitas Linguarum 42, N. Levkovych and A. Urdze, Bremen: Brockmeyer, 2017.

[30] H. Rohde, "Rhetorical Questions as Redundant Interrogatives," Sand Diego Linguistic Papers, pp. 134-168, 2006. 